\title{
IDENTITAS DAN STIGMA SOSIAL DALAM CERPEN “BILA JEBRIS ADA DI RUMAH KAMI" KARYA AHMAD TOHARI
}

\author{
M. Yoesoef \\ Universitas Indonesia \\ email: yoesoev@ui.ac.id
}

\begin{abstract}
(Title: Identity and Social Stigma in Short Story's “Bila Jebris Ada di Rumah Kami" by Ahmad Tohari). Identity becomes a meaningful issue when a crisis occurs. Identity basically talks about ownership about what is generally owned and the difference with others. In the issue of identity there are problems with location, relationships, and involvement with others. The emergence of identity problems is in line with the growth of society as a consequence of migration, urbanization, and transmigration. On the other hand, the problem of identity is also triggered by awareness of gender, ethnicity, social class, and race. Therefore, identity in modern society is an important issue in the social sciences and humanities. The issue of identity in the pragmatic stage is illustrated through a variety of communities, mass media, films, or literature. Among those things, one of the potential media to express the problem of identity is literary work. There are many Indonesian literary works that question identity as an issue, one of which is a short story by Ahmad Tohari entitled "If Jebris Is in Our Home" (1991). This article discusses how the identity of a woman as a prostitute has created social problems for villagers. The social stigma is interesting to discuss from various social, religious, and human perspectives that may be interrelated or conflict with each other. The analysis of the short story shows that the resistance of the villagers to Jebris is based on religious thought and the principle of social harmony in the village.
\end{abstract}

Keywords: identity, urban, religious, stigma

\section{PENDAHULUAN}

Identitas menjadi satu isu yang bermakna manakala terjadi suatu krisis. Identitas pada dasarnya berbicara mengenai kepemilikan tentang apa yang secara umum dimiliki atau dilekatkan kepada seseorang. Identitas yang dilekatkan kepada seseorang itu menjadi jelas posisinya dalam konteks persamaan dan perbedaannya dengan yang lain. Di dalam persoalan identitas itu tercakup juga dengan lokasi, relasi, dan interaksi dengan yang lain. Oleh karena itu, munculnya permasalahan terkait dengan identitas itu berhubungan dengan pertumbuhan masyarakat sebagai konsekuensi adanya migrasi, urbanisasi, dan transmigrasi. Di sisi lain, permasalahan identitas dipicu oleh adanya kesadaran yang kuat terhadap gender, etnisitas, kelas sosial, dan ras. Dengan demikian, identitas dalam masyarakat modern menjadi yang penting dalam diskursus ilmu sosial dan humaniora.
Persoalan identitas itu dalam ranah pragmatis tergambar melalui berbagai wahana, seperti komunitas, media massa. Sementara itu, berbagai persoalan identitas secara sosial maupun budaya diekspresikan melalui film dan sastra. Maraknya komunitas yang dibangun oleh sekelompok orang yang memiliki kesamaan hobi, kegemaran, atau alumni misalnya membentuk sebuah identitas kelompok. Dalam hal media massa, sejumlah majalah atau terbitan berkala secara jelas menunjukkan kalangan pembacanya, misalnya 'majalah wanita,' 'majalah penikmat kopi,' atau majalah remaja.'

Dalam pada itu, ekspresi berbagai permasalahan sosial dan budaya terkait dengan identitas diungkapkan melalui karya seni, antara lain melalui film dan karya sastra. Sejumlah film yang mengungkapkan persoalan identitas di antaranya adalah film "Cek Toko Sebelah," "3 Hati 2 Dunia 1 Hati," atau 
“Ayat-Ayat Cinta 2" Di dalam ketiga film itu diungkapkan bagaimana identitas seseorang dihadirkan bersama dengan berbagai identitas budaya, sosial, etnik, dan ras. Demikian juga di dalam karya sastra persoalan identitas menjadi isu yang menarik para sastrawan. Sejumlah karya sastra yang mengungkapkan persoalan identitas antara lain Salah Asuhan karya Abdul Muis atau cerita pendek Martin Aleida "Ode untuk Selembar KTP" misalnya, yang mengemukakan bagaimana identitas tokoh cerita itu menjadi permasalahan dalam kehidupannya selepas dari penjara.

Di antara karya sastra yang membahas persoalan identitas itu, salah satunya adalah sebuah cerita pendek karya Ahmad Tohari berjudul "Bila Jebris Ada di Rumah Kami" (1991). Cerita pendek itu pernah dimuat dalam majalah Kartini Nomor 443 Tahun 1991. Kemudian cerita pendek itu menjadi salah satu cerita pendek pilihan dalam kumpulan cerita pendek Ahmad Tohari berjudul Mata yang Enak Dipandang (2013).

\section{METODE}

Pemilihan satu cerita pendek karya AhmadTohari, "BilaJebrisAdadiRumahKami" dalam artikel ini dengan mempertimbangkan kuatnya persoalan identitas yang dilekatkan kepada individu tokoh yang kemudian berdampak secara sosial kepada lingkungan di sekitarnya. Persepsi masyarakat yang negatif mengenai sesuatu hal melahirkan stigma yang mampu membingkai (framing) individu atau sekelompok orang atas sesuatu tersebut. Stigma terebut dapat dilekatkan pada berbagai hal yang bersifat sosial, budaya, atau politik. Stigma-stigma itu umumnya dikaitkan dengan berbagai fenomena sosial, budaya, politik yang terjadi di tengah kehidupan masyarakat dan mempengaruhi sendi-sendi bermasyarakat, bahkan bernegara.

Pendekatan yang digunakan untuk mengkaji cerita pendek dalam artikel ini berfokus pada kajian identitas budaya. Hall (1996) dalam "Introduction: Who Need Identity?"mengemukakan bahwa identitas yang dilekatkan kepada individu dikonstruksi secara sosial dan bersifat cair sehingga diperoleh dua kondisi dari identitas itu, yaitu identitas asal (being) dan identitas akhir (becoming). Lebih lanjut dikatakan, pergerakan identitas itu sendiri merupakan proses yang tidak pernah selesai karena adanya sejumlah faktor yang senantiasa berubah atau berkembang, antara lain lokasi dan lingkungan sosial yang dimasuki, tingkat pendidikan, dan kedudukan atau posisi individu sebagai subjek yang senantiasa berubah dari waktu ke waktu (Hall, 1996:2). Dalam hal itu, budaya sebagai institusi merupakan wahana untuk terjadinya relasi kuasa dan intervensi sosial, yang mampu membangun persepsi budaya pada para anggotanya.

Di pihak lain, teks sastra sebagai realitas literer yang bersumber pada realita sosial dan budaya tertentu mampu membangun persepsi sekaligus tanggapan kritis terhadap fenomena sosial dan budaya yang berada di luar teks sastra itu. Oleh karena itu, teks sastra merupakan representasi dari berbagai wacana yang dapat ditangkap melalui berbagai pendekatan sehingga melahirkan interpretasi dan pengetahuan yang kaya kepada pembaca.

Metodologi dalam membahas cerita pendek tersebut adalah metode deskriptif analitis, yaitu pertama adalah mendeskripsikan bagian-bagian cerita pendek yang mengungkapkan persoalan terkait dengan identitas tokoh dan latar, kemudian anasiranasir itu dianalisis dan diinterpretasikan secara kualitatif dengan menggunakan sejumlah teori yang relevan untuk memahami persoalan identitas dan stigma sosial dalam cerita pendek karya Ahmad Tohari itu.

\section{HASIL DAN PEMBAHASAN}

Identitas dan stigma sosial dalam karya Ahmad Tohari ini mencakup tiga tokoh, yaitu Jebris, Sar, dan Ratib. Jebris menunjukkan identitas kediriannya sebagai perempuan, janda beranak satu, dan bekerja sebagai pelacur. Berdasarkan pada identitas kediriannya itu, ia mendapat stigma sosial dari masyarakat di lingkungannya. Pengertian stigma itu sendiri berkaitan dengan persepsi buruk seseorang di mata orang lain karena pengaruh lingkungan. Ciri negatif yang menempel pada seseorang dapat mengakibatkan adanya penolakan dari lingkungannya. Kuatnya stigma sosial yang diterima seseorang pada dapat juga 
mempengaruhi keadaan dirinya, antara lain depresi, merasa dikucilkan, tidak percaya diri, atau tidak berharga.

Dalam cerita pendek ini tokoh Jebris adalah seorang perempuan berstatus janda beranak satu. Untuk menghidupi diri dan anaknya ia menjadi pelacur (PSK: Penjaja Seks Komersial). Tidak ada seorang pun di dusun tempat Jebris tinggal yang belum mengetahui profesinya itu. Ia dikatakan oleh penduduk dusun itu telah menghidupkan kembali aib lama yang lekat dengan dusun itu, khususnya di pojok dusun, lokasi aib itu berasal. "Pojok dusun itu yang dulu dikenal sebagai tempat kelahiran pelacur-pelacur" (hlm.21). Riwayat pojok dusun itu sebagai asal muasal aib bersumber pada ibunya Jebris, perempuan penjual gembus (kue singkong yang digoreng berbentuk gelang). Ia berjualan gembus hingga larut malam di sebuah gubuk di pojok dusun. Jebris senang menemani ibunya berjualan. Para pelanggan, yang umumnya laki-laki, sangat senang berkunjung ke warung gembus itu. Di gubuk itulah ibunya Jebris juga kerap digoda para pelanggan.

Ia sering mendengar emaknya bergurau, berseloroh, bahkan cubit-cubitan dengan pelanggan lelaki. Suatu kali ayahnya datang ketika emaknya sedang berpegangan tangan dengan seorang pembeli. Tetapi emaknya tenang saja, bahkan ayahnya hanya menunduk. (hlm. 25)

Dari kutipan tersebut dapat diinterpretasikan bahwa kepelacuran Jebris berasal dari ibunya. Perilaku ibunya itu sebagai bentuk yang ditiru dan menurun kepada Jebris karena ia belajar dari perilaku ibunya yang pernah dilihat atau diingatnya.

Perilaku dan peristiwa yang terjadi pada ibunya Jebris tersimpan pula di benak para tetangga dan penduduk dusun itu sebagai sebuah memori bersama dan menjadi sebuah stigma sosial. Namun demikian, ingatan kolektif yang terbentuk kepada ibunya Jebris (dan kepada Jebris) tidak mempengaruhi persepsi Sar, salah seorang tetangga dan teman Jebris sejak kecil. Ia ingat betul bahwa Jebris kerap berbuat nakal, yaitu ia suka mengambil sabun dan deterjen, bahkan pernah mengambil pakaian dalam Sar yang sedang dijemur. Namun demikian, Sar sebagai tetangga dan teman tetap memberi perhatian yang khusus, antara lain dengan menyokong Jebris dengan beberapa rantang beras.

Tokoh Jebris dalam teks ini identitasnya direpresentasikan sebagai seorang perempuan, janda satu anak, pelacur, anak seorang penjual gembus, dan ketika kecil ia adalah anak yang nakal. Sebelum menjadi janda ia adalah seorang perempuan yang beruntung. Keberuntungan itu berawal ketika ia menikah pada usia enam belas tahun dengan seorang pedagang yang memiliki kios di dekat terminal. Jebris harus menyesuaikan diri dengan suaminya yang nyantri. Ada tiga identitas dasar yang dilekatkan kepada Jebris, pertama sebagai anak kecil (teman bermain Sar); kedua sebagai isteri dari seorang pedagang; dan ketiga sebagai janda cerai yang kemudian menjadi pelacur.

Masa anak-anak Jebris bersama Sar digambarkan bahwa Jebris adalah anak yang nakal. Kenakalannya diungkapkan Sar dalam hal kebiasaan menggunakan barang milik Sar, seperti sabun dan pakaian dalam. Mereka menunjukan keakraban dan saling mendukung. Dukungan Sar kepada tetangga dan sahabatnya itu terus berlangsung manakala Jebris sudah menjanda dan harus menghidupi anaknya dan juga ayahnya. Sar membiarkan kamar mandinya dipakai karena Jebris tidak memiliki sumur dan kamar mandi sendiri. Dari bagian itu, terlihat bahwa Sar adalah seorang sahabat yang peduli. Kepeduliannya itulah yang membawa kemasgulan ketika selentingan bahwa Jebris sudah menjadi pelacur.

Identitas kedua Jebris adalah sebagai seorang istri. Ia menikah dengan seorang pedagang yang memiliki toko kelontong tidak jauh dari terminal. Jebris menikah pada usia 16 tahun setelah ibunya meninggal dunia dan terpaksa keluar dari Sekolah Rakyat. Suami Jebris yang nyantri memberi identitas baru kepada Jebris melalui busana yang dikenakannya. Sebagai isteri santri, Jebris memakai kebaya panjang dan kerudung dengan aksesori gelang dan kalung emas. Perfomativitas Jebris tersebut menunjukan 
bahwa identitasnya sebagai seorang istri pedagang ditunjang oleh penampilannya dalam berpakaian dan aksesorisnya sekaligus menunjukkan kelasnya.

Untuk hal itu, dapat dipahami bagaimana identitas ditampilkan melalui performativitas ekspresif, sebagaimana identitas kefemininan tampil melalui pakaian, pilihan warna, atau cara berjalan (Weedon 2004:7). Lambat laun, kepercayaan suaminya semakin besar dan ia pun dipercaya untuk menjaga kiosnya yang lumayan besar.

Keelokan dan keramahan Jebris mendatangkan para pelanggan ke kiosnya. Ia hangat terhadap sopir-sopir, kernet-kernet, tukang-tukang ojek, dan para pemuda. Hal itu menimbulkan selentingan bahwa Jebris meniru emaknya berdagang. Kiosnya selalu meriah dengan irama musik dan gelak tawa anak-anak muda. Lalu, terdengar bahwa Jebris sering menghilang bersama Gembyok, tukang ojek yang langsing dan berkulit manis. Akibatnya ia diceraikan suaminya dan Jebris pun kembali ke rumah ayahnya. Situasi itu membawa Jebris ke identitas ketiga, yaitu sebagai janda beranak satu. Ia harus merawat dan menghidupi anak (Mendol) dan ayahnya yang sakit-sakitan. Kehidupan yang sulit dank eras itu membawa Jebris ke dunia pelacuran. Melacur bagi Jebris merupakan pekerjaan untuk bertahan hidup, memberi kehidupan kepada Mendol dan ayahnya yang sudah tua dan tak memiliki pekerjaan. Kepelacuran Jebris memang menunjukkan suatu aktivitas rutin sehari-hari. Ia dengan konsisten menekuni pekerjaannya itu dengan pola sebagaimana pada kutipan berikut.

Tiap sore Jebris naik bus ke daerah batas kota, sekitar terminal, yang pada malam hari menjadi wilayah mesum. Menjelang matahari terbit, Jebris sudah berada di rumah karena selalu menumpang bus paling awal [...] Lalu sering terjadi Jebris berpapasan dengan anak-anak yang mau mengaji di surau menjelang magrib dan bertemu lagi dengan anak-anak itu lepas subuh. (hlm. 22-23)

Kutipan di atas menunjukkan adanya pengkontrasan antara perilaku Jebris dengan anak-anak yang terkait dengan waktu masingmasing. Sore hari Jebris pergi melacur, pada saat yang sama anak-anak pergi mengaji di surau; pagi hari Jebris kembali dari melacur dan anak-anak selesai shalat subuh. Wacana yang dihadirkan di dalam teks memang bermain di ranah antara duniawi dan surgawi, antara yang profan dan yang religius. Narasi sebagai pada kutipan di atas itu diungkapkan juga di bagian lain

Di pojok dusun itu mungkin hanya Sar, istri Ratib, yang benar-benar sedih melihat Jebris. Sar dan Jebris bertetangga sejak bocah, bahkan sampai sekarang pun mereka tinggal sepekarangan, hanya terpisah oleh surau itu, surau yang dipimpin oleh Ratib, suami Sar. Selain menjadi imam surau, Ratib juga menjadi ketua seksi pembinaan rohani dalam kepengurusan RT. Maka ada orang bilang kepelacuran Jebris mencolok mata Ratib, suami Sar. (hl. 23)

Wacana yang dibangun pada kutipan tersebut mengarahkan bahwa ada sejumlah orang mengklaim bahwa perilaku Jebris melacur di rumahnya bertolak belakang dengan religiositas yang dibangun di dusun itu, khususnya berkait dengan pekerjaan Ratib. Dalam hal itu, sudah tergambar dengan jelas identitas riligius yang dilekatkan kepada Ratib, selain sebagai suami Sar. Melalui pekerjaannya, identitas Ratib adalah pembina rohani dan imam surau. Identitas seseorang dimungkinkan dibaca melalui tanda-tanda budaya yang terlihat melalui busana, busana yang terkait pekerjaan. Semuanya itu merupakan dimensi visual identitas seseorang atau sekelompok orang (Weedon, 2004: 1). Pekerjaan dan jenis busana yang dikenakan pun dapat memberi gambaran identitasnya, bahkan mampu membangun stigma sosial dari visualisasi identitas tersebut sesuai dengan ruang budayanya.

Ruang budaya yang direpresentasikan melalui tempat, seperti pojok dusun, surau, terminal, warung, dan rumah mengarahkan pada suatu persepsi dan stigma tentang tempattempat tersebut. Lokasi pertama adalah pojok dusun. Di lokasi itu dahulu ditengarai sebagai sumber lahirnya para pelacur di dusun itu sehingga untuk menghilangkan citra mesum 
terkait dengan lokasi itu, kemudian dibangun surau. Dengan adanya surau itu dipersepsikan akan mengubah fungsi lokasi pojok dusun sebagai tempat mesum diubah menjadi bercitra positif. Identitas yang dilekatkan kepada lokasi tersebut dikonstruksi secara sosial sebagai bentuk perlawanan terhadap stigma sosial yang negatif. Lokasi kedua, terlihat melalui pembingkaian religi melalui surau yang merupakan tempat ibadah dan aktivitas religiositas yang diciptakan di surau itu secara perlahan membentuk memori baru kepada penduduk setempat. Dalam konteks itu, terasa benar adanya kontestasi wacana antara tempat mesum dengan tempat suci.

Lokasi ketiga, yaitu terminal, yang berfungsi sebagai tempat bus-bus mangkal sering juga dibingkai sebagai kawasan para pelacur menjajakan dirinya dan kemudian mendapat label sebagai daerah lokalisasi. Lokasi keempat warung yang hadir dalam konteks ibu Jebris yang menjual gembus, dan ketika Jebris menunggui toko kelontong miliknya bersama suami. Pada kedua lokasi itu (warung dan toko) dihadirkan sebuah stigma melalui perilaku tokoh (ibunya dan Jebris) yang mampu mendatangkan paralelaki dan terjadinya skandal seksual antara para perempuan itu dengan laki-laki yang kerap datang ke warung atau toko tersebut. Lokasi kelima adalah rumah yang dapat dimaknai sebagai tempat tinggal keluarga. Dalam konteks itu, rumah memiliki identitas budaya karena di sanalah tempat terjadinya internalisasi nilai-nilai yang dianut, baik secara sosial maupun budaya setempat. Rumah adalah institusi budaya tempat relasi suami-isteri dalam konteks ikatan keluarga besarnya. Melalui tempat-tempat itu terbangun sebuah identitas yang dilekatkan kepada individu-individu yang terikat dengan ruang budaya itu. Week (1990:88) mengemukakan bahwa:

Identitas berkaitan dengan kepemilikan, tentang apa yang dimiliki secara umum oleh sejumlah orang dan apa perbedaan seseorang dari lainnya. Melalui hal itu, yang paling mendasar adalah memaknai secara personal mengenai lokasi sebagai hal yang paling stabil untuk menandai keindividuan seseorang. Namun demikian, semua itu berkaitan juga dengan relasi sosial ketika seseorang berada dengan lainnya di suatu tempat [...] Setiap kita hidup dengan berbagai potensi identitas yang boleh jadi saling berkontradiksi yang membuat kita memahami identitasnya masing-masing.

Persoalan lokasi menjadi faktor penting dalam hal membangun identitas sekaligus stigma sosial ketika terminal diidentikkan dengan identitas Jebris sebagai pelacur. Terminal distigmatisasi sebagai wilayah mesum di samping sebagai tempat bus-bus mangkal. Terminal juga dikaitkan dengan para sopir yang kerap juga distigmatisasi sebagai klien para pelacur itu. Hal ini dapat dianalogikan dengan kawasan pantura Jawa sebagai kawasan yang ramai dilalui truk-truk pengangkut berbagai kebutuhan masyarakat. Di sepanjang pantura itu tumbuh warung-warung yang sering disinggahi para sopir dan tidak jarang warung-warung itu distigmatisasi sebagai lokasi pelacuran. Dari uraian tersebut di atas, nampak jelas bahwa identitas yang dimiliki Jebris membangun berbagai stigma sosial terhadap dirinya dan juga terhadap sejumlah lokasi yang ada di dalam cerita pendek ini.

Selain lokasi yang dapat menandai identitas seseorang adalah relasi sosial sebagai ranah bersama. Para sosialita, misalnya, membangun identitasnya melalui berbagai kegiatan bersama. Hal itu berarti pula bahwa seseorang yang berada di luar identitas komunitasnya dapat dibedakan dari berbagai faktor, antara lain perilaku berbusana, jenis barang yang dibawa, jenis makanan, dan lokasi pertemuan. Semua itu membangun wacana identitas yang boleh jadi dapat dikontestasikan satu sama lain.

Kontestasi wacana serupa hadir pula di dalam cerita pendek itu, yaitu dalam bentuk persepsi Sar ketika mendengar selentingan bahwa Jebris melacur. Ia melontarkan sebuah wacana tentang keberkahan. Hal keberkahan mencuat ketika ia khawatir bahwa keberkahan atas keluarganya tidak akan ada lagi jika Jebris melacur di lingkungan rumahnya (konon Jebris sudah berani membawa lelaki ke rumahnya). 
Sar mengonfirmasi kekhawatirannya itu kepada Ratib, suaminya yang menjadi pembina rohani di dusun itu.

Dari situ, persoalan kemudian beralih pada wacana "Bila Jebris ada di rumah mereka (Sar dan Ratib) apakah keberkahan akan jauh dari kehidupan mereka?" Nampaknya, bagi Sar yang dipentingkan adalah soal kehidupannya yang penuh dengan berkah Tuhan. Namun demikian, hal yang juga mengemuka dalam bagian cerita pendek itu bahwa hal yang paling penting bukanlah dalam kehidupan personal tetapi kehidupan di dalam komunitas. Kepentingan bersama dalam suatu komunitas adalah hadirnya hidup yang harmonis dan tenteram. Perilaku Jebris, sebagai pelacur, masih dapat mereka toleransi, tetapi ketika Jebris sudah berani menerima tamu di rumahnya menunjukkan sebuah pelanggaran yang dapat menggangu ketenteraman dan keharmonisan bertetangga. Melalui komunitas itulah dibangun suatu identitas bersama. Dalam perspektif itulah Sar memandang bahwa Jebris menjadi ancaman terhadap apa yang Sar pernah dengar tentang berkah Tuhan kepada keluarga.

"Kang Ratib, kata orang, keberkahan tidak akan datang pada empat puluh rumah di sekitar tempat mesum. Apa iya, Kang?"

"Ya, mungkin."

"Kalau begitu, hidup kita tidak bisa berkah, ya, Kang?"

"Maksudmu selentingan terbaru tentang Jebris?"

Sar mengangguk. Ratib menarik napas panjang. Sar menunggu tanggapan, tetapi suaminya hanya menjawab dengan senyuman. (hlm. 24)

Sar berupaya mempertahankan identitas yang dimilikinya sebagai bagian dari komunitas masyarakat dusun yang bebas dari tindak prostitusi. Sementara itu, Jebris ditautkan dengan identitas yang terkait dengan pekerjaannya sebagai seorang pelacur. Hal itu berbeda dengan kebanyakan perempuan di dusun itu yang tidak melacurkan diri. Identitas keduaperempuanitumerupakanrealitayangada di dalam relasi sosial mereka, terutama sebagai tetangga dan sebagai teman sejak kecil. Ketika mereka kecil tidak ada pembatasan identitas keduanya. Mereka bertetangga dan menjadi teman bermain. Di kemudian hari terjadi perubahan sesuai yang disebabkan sejumlah faktor yang mempengaruhi perubahan identitas masing-masing. Sar menjadi seorang guru, Jebris menjadi seorang pelacur. Kepentingan keduanya yang bertolak belakang secara pekerjaan menunjukkan sejumlah wacana yang hadir di dalam cerita pendek itu. Kontestasi antarwacana menjadi sebuah diskusi moral, sosial, religi, dan juga kemanusiaan. Hal yang terakhir, mengenai wacana kemanusiaan dinyatakan melalui peristika tidak pulangnya Jebris dalam dua hari terakhir. Hal itu menumbuhkan kekhawatiran ayahnya sehingga mendatangi Ratib, tetangganya.

Rasa empati Ratib manakala ayahnya Jebris yang mengabarkan bahwa sudah dua hari Jebris tidak pulang ke rumah dan ia tidak tahu harus berbuat apa. Menghadapi situasi seperti itu, Ratib berinisiatif untuk menjemput Jebris di Kantor Polisi. Kemungkinan besar Jebris ditangkap polisi saat ada razia. Situasi itu pula yang membawa Ratib dan Sar berada dalam dilema antara wacana kemanusiaan dan wacana keberkahan sebagaimana diungkapkan pada bagian berikut.

\footnotetext{
"Kang Ratib, jadi kamu hendak mengambil Jebris dari kantor polisi?"

"Ya. Dan kuharap kamu tidak keberatan." "Lalu?"

"Juga bila kamu tidak keberatan; Jebris kita coba ajak bekerja di rumah kita.

Mungkin dia bisa masak dan cuci pakaian."

"Andai dia mau; apakah kamu tidak merasa risi ada pelacur di antara kita?”

"Yah, ada risinya juga. Tetapi mungkin itu jalan yang bisa kita tempuh."

"Bila Jebris tidak mau?"

"Kita akan terus bertetangga dengan dia. Dan kamu tak usah khawatir malaikat pembawa berkah tidak akan datang ke rumah ini bila kamu tetap punya kesabaran dan sedikit empati terhadap anak penjual gembus itu." (hlm. 28)
}

Cerita pendek "Bila Jebris Ada di Rumah Kami" mendorong Sar pada situasi marjinal. Ia berada pada suara mayoritas 
penduduk dusun, suara moralitas melawan ketidakbermoralan, dan suara kemanusiaan dan kepercayaan atas religiositas agamanya. Identitas yang dilekatkan kepada para tokoh dalam cerita pendek, yaitu pelacur (Jebris), guru (Sar), dan imam surau (Ratib) ini pun membuka sebuah diskusi mengenai identitas dan stigma sosial yang terbangun semata-mata untuk membedakan identitas masing-masing dalam ruang budaya mereka.

\section{SIMPULAN}

Ahmad Tohari melalui cerita pendek "Bila Jebris Ada di Rumah Kami" membawa ke permukaan mengenai kuatnya stigma yang dibangun oleh identitas seseorang, dalam hal ini tokoh Jebris, seorang pelacur. Kepelacuran Jebris menandai aib yang selama ini sudah dikubur di dusun itu, yang konon di pojok dusun itu pernah menjadi penghasil para pelacur. Untuk membentuk identitas baru dusun itu dibangunlah sebuah surau yang dimaknai mampu mendatangkan citra positif bagi pojok dusun itu. Identitas Jebris dibangun oleh lingkungan yang sekaligus melahirkan stigma sosial terhadap dirinya.

Jebris memiliki sejumlah identitas yang dimilikinya selaras dengan perjalanan waktu, yaitu sebagai anak yang seenaknya ketika bocah bersama Sar; sebagai istri pedagang yang memberinya kesempatan menikmati kehidupan yang baik; sebagai perempuan penggoda ketika menjadi penjaga toko kelontong milik suaminya; sebagai janda beranak satu ketika dicerai suaminya; dan sebagai pelacur sebagai cara mempertahankan diri untuk menghidupi keluarganya.

Berbagai hal yang terjadi kepada Jebris berdampak kepada Sar sebagai teman sekaligus tetangganya. Dilema yang dihadapi Sar muncul ketika Ratib, suaminya, berinisiatif menjemput Jebris dari kantor polisi dan mengusulkan kepada Sar untuk mempekerjakan Jebris di rumahnya atau tetap bertetangga tanpa khawatir malaikat tidak membawa keberkahan ke rumahnya. Persepsi religiositas Sar itu ditepis dengan empati kemanusiaan Ratib, yang juga menjadi Pembina rohani di dusun itu.
Cerita pendek ini juga menghadirkan kontestasi wacana yang dibangun melalui narasi dan identitas tokoh-tokohnya, terutama kontestasi antara wacana yang dibangun Sar dan wacana stigma yang dilekatkan kepada Jebris. Dari situasi itu, Ratib membawa wacananya sendiri di antara kontestasi itu, yaitu wacana kemanusiaan.

Identitas para tokoh dalam cerita pendek ini juga dikuatkan representtasinya melalui sejumlah lokasi atau tempat yang erat dengan mereka, yaitu pojok dusun, surau, terminal, warung, toko, dan rumah.

\section{DAFTAR PUSTAKA}

Aleida, M. (2009). Mati Baik-Baik Kawan. Jakarta: Penerbit Ultimus.

Hall, S. (1996). "Introduction: Who Need Identity?" dalam Stuart Hall and Paul du Gay (eds.). Questions of Cultural Identity. London: Sage Publications Ltd.

Hall, S. (1990). Cultural Identity and Diaspora. dalam J. Rutherford. Identity: Community, Culture, Difference. London: Lawrence \& Wishart.

Muis, A. (1925). Salah Asuhan. Jakarta: Balai Pustaka.

Rutherford, J. (1990). Identity: Community, Culture, Difference. London: Lawrence \& Wishart.

Stevenson, D. (2003). Cities and Urban Culture. Berkshire: Open University Press.

Tohari, A. (2013). Mata yang Enak Dipandang. Jakarta: PT Gramedia Pustaka Utama.

Tohari, A. (1991). "Bila Jebris Ada di Rumah Kami. Dalam Mata yang Enak Dipandang (2013). Jakarta: PT Gramedia Pustaka Utama.

Weedon, C. (2004). Identity and Culture: Narratives of DifferenceandBelonging. Berkshire: Open University Press.

Week, J (1990). The Value of Difference Dalam J. Rutherford. Identity: Community, Culture, Difference. London: Lawrence \& Wishart.

Woodward, K. (ed.). 1997. Identity \& Difference. London: Sage. 